\title{
Extraction preconcentration of platinum and ruthenium using high molecular weight amines prior to simultaneous determination by derivative spectrophotometry
}

\author{
M. Balcerzak* and E. Wyrzykowska \\ Department of Analytical Chemistry, Warsaw University of Technology, Noakowskiego 3, \\ 00-664 Warsaw, Poland
}

\begin{abstract}
Platinum and ruthenium can be simultaneously extracted from hydrochloric acid solution by high molecular weight amines (trioctylamine (TOA) or diantipyrylmethane (DAM) in 1,2-dichloroethane) after preliminary conversion into the complexes with $\mathrm{SnCl}_{3}$ - ligands. The determination of both metals in the presence of each other in organic solutions of the formed ion-pairs can be accomplished by applying derivative spectrophotometry. The values of the second derivative spectra at $395 \mathrm{~nm}$ and $437 \mathrm{~nm}$, calculated with the 2-nd degree polynomial and 75 points correspond to the concentration of platinum associated with TOA and DAM, respectively. The value of the second derivatives at $497 \mathrm{~nm}$ and $463 \mathrm{~nm}$ can make a basis of the determination of ruthenium in the presence of platinum in the form of ion-pairs with TOA and DAM, respectively. The use of TOA as extractant ensures higher precision and accuracy of the determination of platinum and ruthenium by derivative spectrophotometry. RSD of the results of the determination of metals in synthetic mixtures does not exceed $2.7 \%$ and $3.2 \%$ for platinum and ruthenium, respectively.

Keywords. Platinum determination - ruthenium determination - extraction preconcentration - tin(II) chloride complexes derivative spectrophotometry.
\end{abstract}

\section{Introduction}

The accurate determination of platinum group metals in various matrices is one of the most difficult analytical problems. Large variety and complexity of examined materials (geological, industrial, biological and environmental), inhomogeneous distribution of metals in the examined samples and wide range of concentrations to be determined (from ppb levels e.g. in biological and environmental materials even up to $99.99 \%$ in some industrial products) make the choice of the analytical procedure to be used a fundamental problem.

Direct use of instrumental techniques for the determination of noble metals is considerably restricted owing to numerous interferences caused by various types of matrices. Separation of analytes from base elements as well as particular precious metals from each other usually precedes the final detection $[1,2]$. Due to exceptional ability of ruthenium and osmium to be converted into the volatile tetroxides, $\mathrm{RuO}_{4}$ and $\mathrm{OsO}_{4}$, which can be isolated from the examined samples by distillation, the majority of separation procedures were developed for mixtures of the other metals: platinum, palladium, rhodium, iridium and gold. It should be noted however, that quantitative isolation of ruthenium and osmium from the mixture of noble metals by distillation, in particular from chloride solutions, is a difficult problem. Chloride complexes of both metals do not easily oxidize to volatile species.

Recent applications of two metals, platinum and ruthenium, as effective catalysts in various chemical processes [3] lead to the interest in analytical methods allowing the determination of both metals directly in solutions obtained after digestion of various catalysts. Bimetallic Pt-Ru catalysts are widely applied e.g. in methanol fuel cells capable of changing the chemical energy directly into electrical energy [4-7]. Ruthenium has been successfully applied to promote the catalytic activity of platinum in electro-oxidation reaction of methanol.

Spectrophotometric methods can be employed to the determination of microgram amounts of the metals present in the catalysts. Essential increase in the selectivity of the determination can be achieved by numerical calculation of derivative spectra of the suitable order allowing to isolate the individual signal of particular analytes from their mixtures [8].

Simultaneous extraction of platinum and ruthenium from chloride solutions and direct determination of analytes in the presence of each other in the obtained extract by applying derivative spectrophotometry [9] were the aims of this work.

\footnotetext{
* Correspondence and reprints
}

Received May 27, 1999; revised October 10, 1999; accepted November 2, 1999 
The employing of extraction separation step may allow to preconcentrate platinum and ruthenium prior to their determination.

Extraction is often used for separation and preconcentration of platinum metals [10]. Chloride complexes make a basis of majority of separation procedures. These complexes are the main products of digestion procedures applied to transform noble metals into soluble species. Fire assay, treatment with aqua regia, alkaline oxidizing fusion followed by acidification with hydrochloric acid or direct chlorination are used. Quantitative conversion of particular metals into defined stable complexes provides major difficulties. Various chloro- and aquachlorocomplexes containing elements at various oxidation states can be formed during digestion of the samples in the presence of hydrochloric acid. Different behaviour of particular complexes in separation procedures employed, high tendency for hydrolysis and formation of polynuclear forms make the separation and preconcentration steps the most critical. Interactions of analytes with complexing agents resulting in the formation of stable forms of defined composition which can be used in analytical procedures were widely examined.

Earlier, it was established that platinum and ruthenium in hydrochloric acid medium reacted with $\mathrm{SnCl}_{3}{ }^{-}$ligands and the anionic complexes, $\mathrm{PtCl}_{2}\left(\mathrm{SnCl}_{3}\right)_{2}^{-}$and $\mathrm{RuCl}_{2}\left(\mathrm{SnCl}_{3}\right)_{2}{ }^{-}$, were formed [11,12]. Recent experiments [8] have shown that both metals can be simultaneously transformed into these complexes independently of their form in chloride solutions examined. The complexes have been used in the paper to develop extraction-spectrophotometric methods allowing to preconcentrate both analytes prior to their determination. The extraction of ion pairs of the anionic complexes of platinum and ruthenium with tin(II) chloride and trioctylamine (or diantipyrylmethane) has been examined.

High molecular weight amines, aliphatic and aromatic, have been used earlier as effective extractants of particular noble metals in liquid-liquid extraction and liquid-anion exchanger processes [13-33]. Amines, usually dissolved in organic diluents, are transformed into organic cations $\left(\mathrm{R}_{x} \mathrm{NH}^{+}\right)$by reaction with acids present in aqueous solutions. The cations can react with anionic complexes of the metals existing in solution with the formation of the ion-pairs, dissolved in the organic solvent. The extractability of a given metallic complex depends on the kind of amine used, affinity of the organic solution towards inorganic species, acidity of an aqueous solution and the kind of a diluent used. The use of high molecular weight amines as extraction reagents can allow to isolate the analytes from base metals which can be present in the examined solutions in cationic forms.

Platinum [13-18], palladium [16,17,19,20], ruthenium [21-23] and osmium [23-29] were effectively extracted by various aliphatic amines from the solutions containing their chloride complexes. Aliphatic amines were also used as carriers in liquid membrane separation processes of gold, platinum and palladium [30] and rhodium [31]. Some aromatic amines have also been applied to the extraction of platinum, palladium and rhodium from chloride solutions [32,33]. Attempts to extract platinum [34], palladium [35] and ruthenium [36] from the solutions containing their complexes with $\mathrm{SnCl}_{3}{ }^{-}$groups have been reported.

Derivative spectrophotometry has been applied to determine platinum and ruthenium directly in organic solutions of the ion-pairs examined in the paper. The overlapping absorption spectra of the ion-associates of the complexes with $\mathrm{SnCl}_{3}{ }^{-}$ligands and trioctylamine or diantipirylmethane in 1,2-dichloroethane, used as diluent, were resolved by numerical calculation of the second order derivative spectra. The derivative values corresponding to the concentration of platinum or ruthenium were used to evaluate the content of the analytes in organic solutions obtained.

\section{Experimental results}

\section{Apparatus and reagents}

The absorbance was measured and absorption spectra were recorded using a Hitachi U-3300 spectrophotometer (Japan) with $1-\mathrm{cm}$ cells. The GRAMS/386 software of Galactic Industries Corporation and Savitzky-Golay algorithm were used for calculation the derivative spectra.

Platinum standard solution $\left(1 \mathrm{mg} \mathrm{ml}^{-1} \mathrm{Pt}\right)$ was prepared by dissolving $100.0 \mathrm{mg}$ of platinum $(99.99 \%)$ in $16 \mathrm{ml}$ of aqua regia. The obtained solution was evaporated almost to dryness. $3 \mathrm{ml}$ of conc. $\mathrm{HCl}$ was added and the solution was evaporated once again. The residue was dissolved in $1 \mathrm{M} \mathrm{HCl}$ and the solution obtained was diluted to $100.0 \mathrm{ml}$ with $1 \mathrm{M} \mathrm{HCl}$.

Ruthenium standard solution $\left(1 \mathrm{mg} \mathrm{ml}^{-1} \mathrm{Ru}\right)$ was prepared by fusion of $100.0 \mathrm{mg}$ of powdered ruthenium in a silver crucible with $1 \mathrm{~g}$ of sodium peroxide. The temperature was gradually increased to a dark red glow $\left(\mathrm{ca} .450{ }^{\circ} \mathrm{C}\right)$ and maintained for $10 \mathrm{~min}$. The sample was allowed to cool, dissolved in water, and acidified with conc. $\mathrm{HCl}$. The mixture was heated and the coagulated $\mathrm{AgCl}$ was filtered and washed with $0.1 \mathrm{M} \mathrm{HCl}$. The filtrate was diluted to $100.0 \mathrm{ml}$ with $1 \mathrm{M} \mathrm{HCl}$.

- Tin(II) chloride, $1 \mathrm{M}$ solution in $2 \mathrm{M} \mathrm{HCl}$.

- Trioctylamine, $2 \%$ solution in 1,2-dichloroethane.

- Diantipyrylmethane, $2 \%$ solution in 1,2-dichloroethane.

\section{Procedure}

\section{Determination of platinum and ruthenium with tin(II) chloride and trioctylamine}

The test solution containing platinum and ruthenium in $5 \mathrm{M} \mathrm{HCl}$ was placed into a beaker and tin(II) chloride solution was added to obtain $0.05 \mathrm{M} \mathrm{SnCl}_{2}$ in the final volume of $20 \mathrm{ml}$. The solution was heated at $90{ }^{\circ} \mathrm{C}$ for $45 \mathrm{~min}$, than cooled to room temperature and transfered into a separatory funnel. The solution was shaken for $1 \mathrm{~min}$ with two 5-ml 
portions of TOA in 1,2-dichloroethane. The extracts were placed into a $10-\mathrm{ml}$ volumetric flask.

The spectrum of the obtained organic solution was recorded in the $350-550 \mathrm{~nm}$ against the blank at the following instrumental parameters: interpoint distance $0.2 \mathrm{~nm}$; slit $1 \mathrm{~nm}$, scan speed $120 \mathrm{~nm} \mathrm{~min}{ }^{-1}$. The second derivative spectrum was calculated consecutively (from the first derivative values) using 75 points and a second degree polynomial. The values of the second derivatives at $395 \mathrm{~nm}$ and $497 \mathrm{~nm}$ for platinum and ruthenium, respectively were measured. The concentrations of both analytes were evaluated using the appropriate regression equations.

\section{Results and discussion}

\section{Studies on the extraction of platinum-tin(II) chloride complex by TOA and DAM}

The experiments have shown that platinum after conversion into the anionic complex with tin(II) chloride reacts with both examined amines, trioctylamine and diantipyrylmethane. The formed ion-pair passes into the organic phase while shaking the aqueous solution with the extractant dissolved in a suitable organic solvent. 1,2-dichloroethane was chosen as a diluent of both amines used. Carbon tetrachloride and chloroform were also examined for this purpose. Easy formation of emulsion during shaking aqueous solutions with both extractants dissolved in these solvents eliminated their use in extraction procedure.

Platinum is extracted quantitatively by examined amines from a medium of 1-7 M HCl. It turned out however, that organic solutions of the ion pair containing TOA as counter ion were more stable after extraction from the solutions of 3-7 $\mathrm{M}$ hydrochloric acid. $5 \mathrm{M} \mathrm{HCl}$ was chosen as optimum for extraction with the use of TOA. Quantitative extraction of platinum with DAM can be carried out from lower hydrochloric acid concentration. $2 \mathrm{M} \mathrm{HCl}$ was used in the paper.

The extraction of platinum was complete while 2-5\% solutions of TOA or DAM in 1,2-dichloroethane and $1 \mathrm{~min}$ shaking time of aqueous to organic phases were applied. Slight increase in absorbance of the blanks, from 0.01 to 0.05 , was observed with the increase of the concentration of particular extractants in solutions used.

TOA extracts platinum quantitatively up to aqueous to organic phase $\mathrm{V}_{a q}: \mathrm{V}_{\text {org }}=150 \mathrm{ml}: 10 \mathrm{ml}$ volume ratio. Lower, by a factor of 2, preconcentration coefficient can be reached while DAM is used for extraction.The organic solutions of both ion-pairs examined are stable for $60 \mathrm{~min}$. Maximum absorbance of the complex of platinum with TOA and DAM corresponds to $400 \mathrm{~nm}$ and $405 \mathrm{~nm}$, respectively.

Platinum can be determined in organic solutions obtained by direct spectrophotometry. The solutions of both ion-pairs obey Beer's law up to $30 \mu \mathrm{g} \mathrm{ml}^{-1} \mathrm{Pt}$. The sensitivity of the determination is similar in both examined systems. Molar absorptivities equal to $9.08 \times 10^{3}$ and $8.96 \times 10^{3} 1 \mathrm{~mol}^{-1} \mathrm{~cm}^{-1}$ for TOA and DAM, respectively. The regression equations are:

$$
\begin{gathered}
y=0.0452 c+0.0119 \text { and } \\
y=0.0451 c+0.0159
\end{gathered}
$$

(where $y$ is an absorbance and $c$ is the concentration of platinum) for the system with TOA and DAM, respectively.

\section{Studies on the extraction of ruthenium-tin(II) chloride complex by TOA and DAM}

It has been established that ruthenium in the form of the complex with tin(II) chloride can also be extracted by TOA or DAM under the same as platinum conditions. Extraction of ruthenium is complete during 1 min shaking of the aqueous phase with $2-5 \%$ solution of particular amines in 1,2dichloroethane. The stability of the organic solutions of the ion-pairs of ruthenium is higher as compared with the solutions of platinum complexes. No changes in spectra of the ruthenium ion-pairs with TOA or DAM were observed within 2 days. It has been established that the extraction of ruthenium is quantitative up to $\mathrm{V}_{a q}: \mathrm{V}_{\text {org }}=150 \mathrm{ml}: 10 \mathrm{ml}$ in the system with DAM and $25 \mathrm{ml}: 10 \mathrm{ml}$ while TOA is used as extractant.

The organic solutions of both ion-pairs can make a basis of the determination of ruthenium by direct spectrophotometry. The solutions obey Beer's law up to $30 \mu \mathrm{g} \mathrm{ml}{ }^{-1} \mathrm{Ru}$. Maximum absorbances of the complexes with TOA and DAM correspond to $450 \mathrm{~nm}$ and $455 \mathrm{~nm}$, respectively. The regression equations are:

$$
\begin{gathered}
y=0.0253 c+0.006 \text { and } \\
y=0.0267 c+0.0127
\end{gathered}
$$

(where $y$ is an absorbance and $c$ is the concentration of ruthenium) for the system with TOA and DAM, respectively.

\section{Determination of platinum and ruthenium in mixtures by derivative spectrophotometry}

The experiments have shown that the examined $\mathrm{Pt}(\mathrm{Ru})$ $\mathrm{SnCl}_{2}$-TOA(DAM) systems can make a basis of simultaneous extraction of platinum and ruthenium from the solutions of their binary mixtures. The use of derivative spectrophotometry allows the determination of platinum and ruthenium in the presence of each other in organic solutions of the ionpairs examined. Direct spectrophotometric determination of platinum and ruthenium in the same solutions is not possible due to overlapped absorption spectra of the examined complexes (Fig. 1a and Fig. 3a). It has been established that the calculation of derivative absorption spectra of mixtures of the complexes of platinum and ruthenium with tin(II) chloride and TOA or DAM allows to isolate the individual absorption band of particular ion-pairs examined. The GRAMS/386 software of Galactic Industries Corporation and the Savitzky-Golay algorithm [37] was used for calculation of derivative spectra in this paper. The use of a 


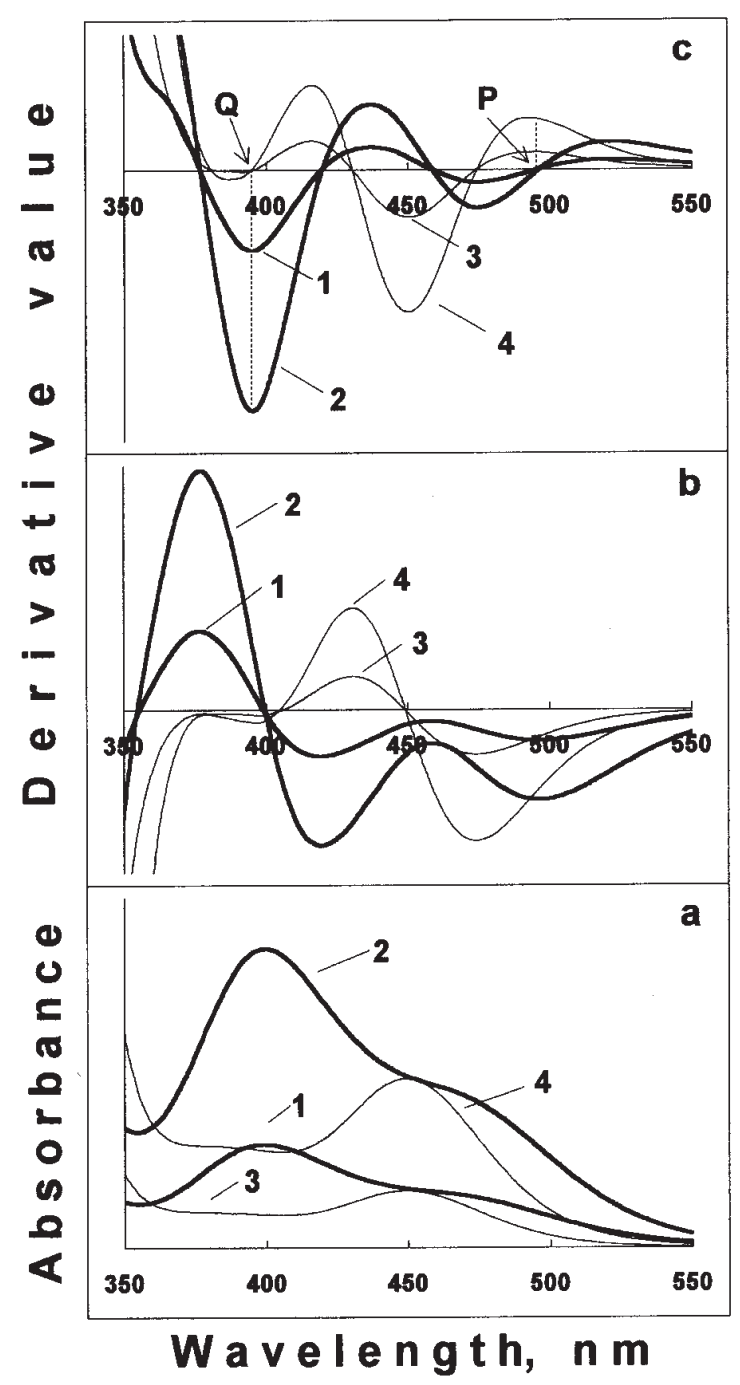

Fig. 1. Direct (a) and derivative (first- (b) and second-order (c)) spectra of the ion-pairs of platinum $\left(10\right.$ and $30 \mu \mathrm{g} \mathrm{ml} l^{-1} \mathrm{Pt}$, curves 1 and 2 , respectively) and ruthenium (10 and $30 \mu \mathrm{g} \mathrm{ml}^{-1} \mathrm{Ru}$, curves 3 and 4 , respectively) with tin(II) chloride and TOA in 1,2dichloroethane.

second degree polynomial and 75 points allows to obtain satisfactory smoothed derivative spectra.

\section{Determination of platinum and ruthenium in the Pt-Ru-SnCl${ }_{2}-\mathrm{TOA}$ system}

It has been established that applying the second order derivative spectrophotometry and "zero-crossing" technique allows to evaluate the concentration of platinum and ruthenium present in the same solution. The second derivative spectrum of the ruthenium-tin(II) chloride-TOA ion-pair, calculated consecutively from the first derivative spectrum, crosses the zero line at $395 \mathrm{~nm}$ (Fig. 1c - point Q). The value of the second derivative spectrum of mixture of platinum and ruthenium at this wavelength corresponds only to the

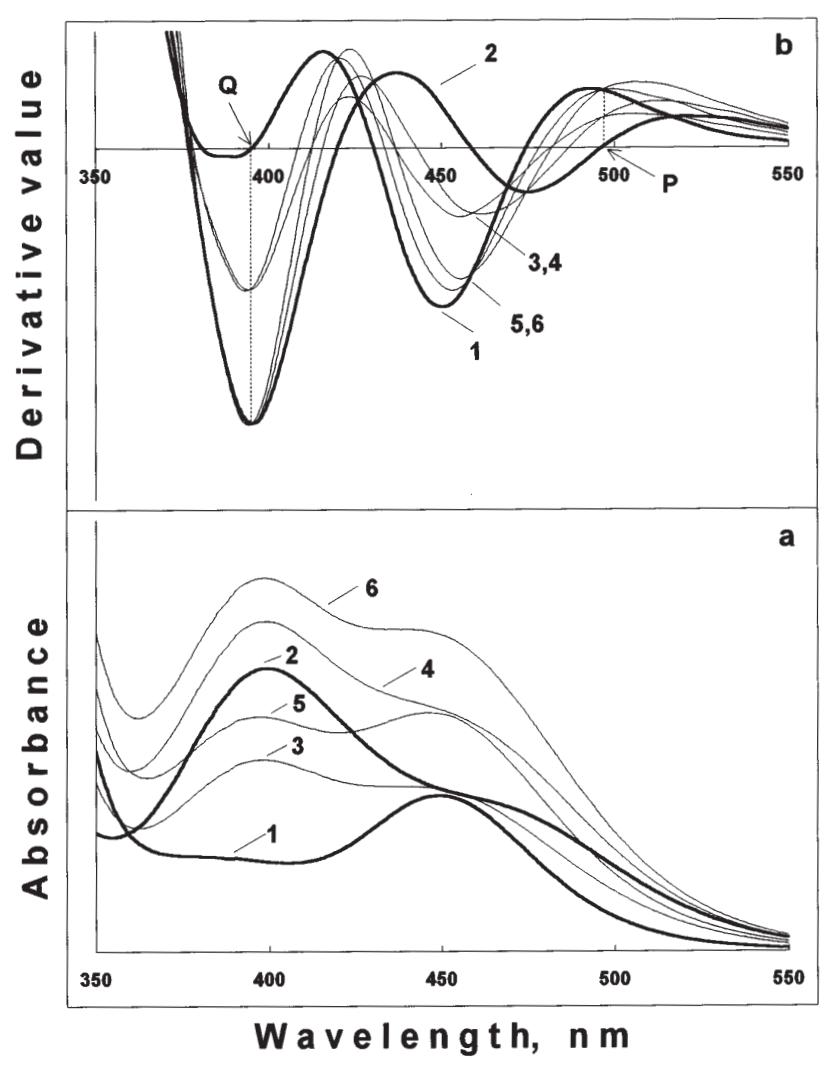

Fig. 2. Direct (a) and second-order (b) derivative spectra of the ion-pairs of ruthenium $\left(20 \mu \mathrm{g} \mathrm{ml}^{-1} \mathrm{Ru}-\right.$ curve 1$)$ and platinum $\left(20 \mu \mathrm{g} \mathrm{ml}^{-1} \mathrm{Pt}\right.$ - curve 2) with tin(II) chloride and TOA in 1,2dichloroethane; and their mixtures: $10 \mu \mathrm{g} \mathrm{ml}^{-1} \mathrm{Ru}+\left(10 \mu \mathrm{g} \mathrm{ml}{ }^{-1} \mathrm{Pt}\right.$ and $20 \mu \mathrm{g} \mathrm{ml}^{-1} \mathrm{Pt}$ - curves 3 and 4 , respectively); $20 \mu \mathrm{g} \mathrm{ml}^{-1} \mathrm{Ru}+$ (10 $\mu \mathrm{g} \mathrm{ml}^{-1} \mathrm{Pt}$ and $20 \mu \mathrm{g} \mathrm{ml}^{-1} \mathrm{Pt}$ - curves 5 and 6 , respectively).

concentration of platinum in the examined solution (Fig. 2b). The organic solutions obey Beer's law up to $30 \mu \mathrm{g} \mathrm{ml}^{-1} \mathrm{Pt}$. The regression equation for the calculation of the content of platinum is:

$$
y=2.37 \times 10^{-6} c-1.39 \times 10^{-7}
$$

(where $y$ is the second derivative value at $395 \mathrm{~nm}$ and $c$ is the concentration of platinum). The correlation coefficient $\mathrm{R}^{2}=0.9998$.

Ruthenium can be determined in the same solutions on the basis of the second derivative values at $497 \mathrm{~nm}$ ("zerocrossing" point of the spectrum of platinum-tin(II) chlorideTOA ion-pair) (Fig. 1c and $2 b-$ point $P$ ). The second derivatives of the spectrum of ruthenium complex at this wavelength obey Beer's law up to $30 \mu \mathrm{g} \mathrm{ml}^{-1} \mathrm{Ru}$. The regression equation is:

$$
y=4.77 \times 10^{-7} c+1.93 \times 10^{-7} ; \mathrm{R}^{2}=0.9999
$$




\section{Original articles}

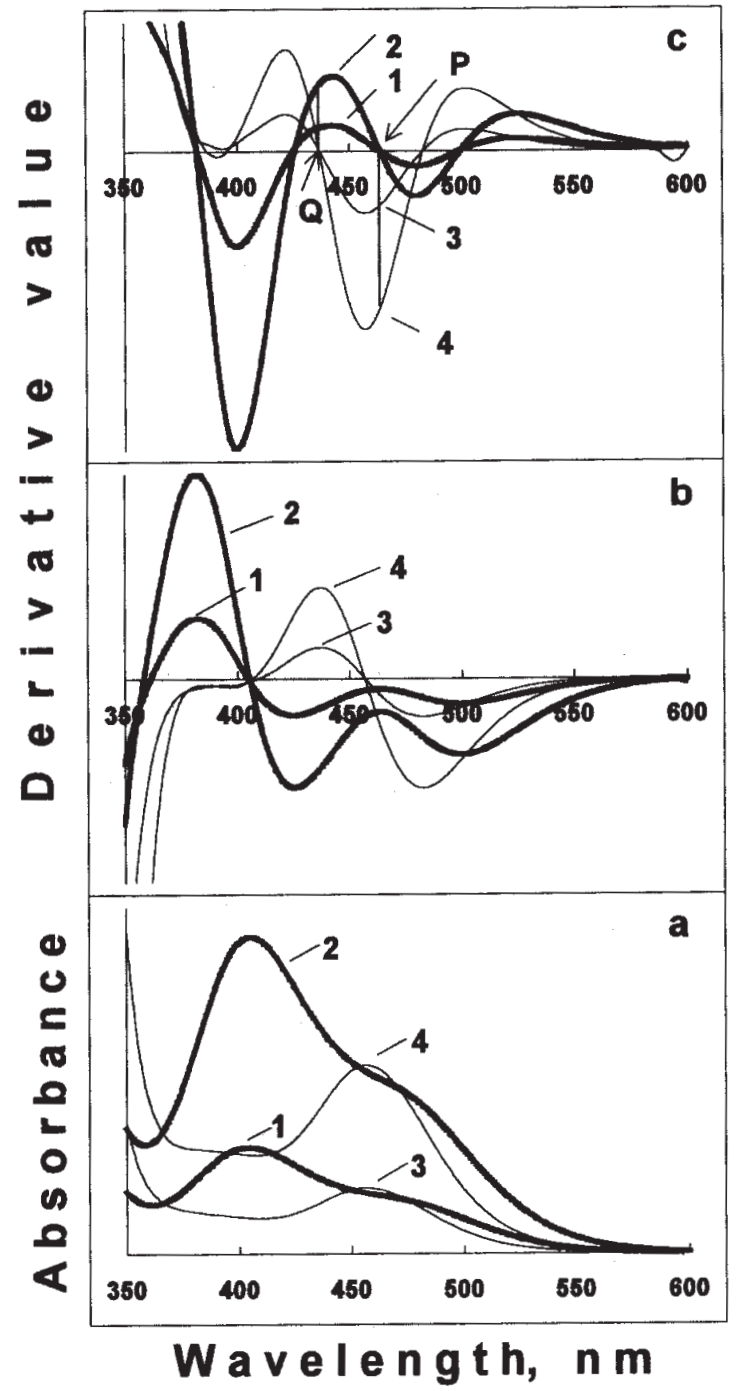

Fig. 3. Direct (a) and derivative (first- (b) and second-order (c)) spectra of the ion-pairs of platinum (10 and $30 \mu \mathrm{g} \mathrm{ml}^{-1} \mathrm{Pt}$, curves $l$ and 2 , respectively) and ruthenium (10 and $30 \mu \mathrm{g} \mathrm{ml}^{-1} \mathrm{Ru}$, curves 3 and 4, respectively) with tin(II) chloride and DAM in 1,2dichloroethane.

\section{Determination of platinum and ruthenium in the Pt-Ru-SnCl2-DAM system}

It was established that the use of derivative spectrophotometry allowed to isolate the individual signals of platinum and ruthenium from mixtures of their ion-pairs with DAM. The second derivative spectrum of ruthenium-tin(II) chlorideDAM complex crosses the zero-line at $437 \mathrm{~nm}$ (Fig. 3c point Q). The absorbance measured at this wavelenght corresponds only to the concentration of platinum in the examined mixtures (Fig. 4b). The regression equation for calculation the concentration of platinum is:

$$
y=5.14 \times 10^{-7} c+3.09 \times 10^{-7} ; \mathrm{R}^{2}=0.9997 .
$$

Beer's law is obeyed up to $10 \mu \mathrm{g} \mathrm{ml}^{-1} \mathrm{Pt}$.

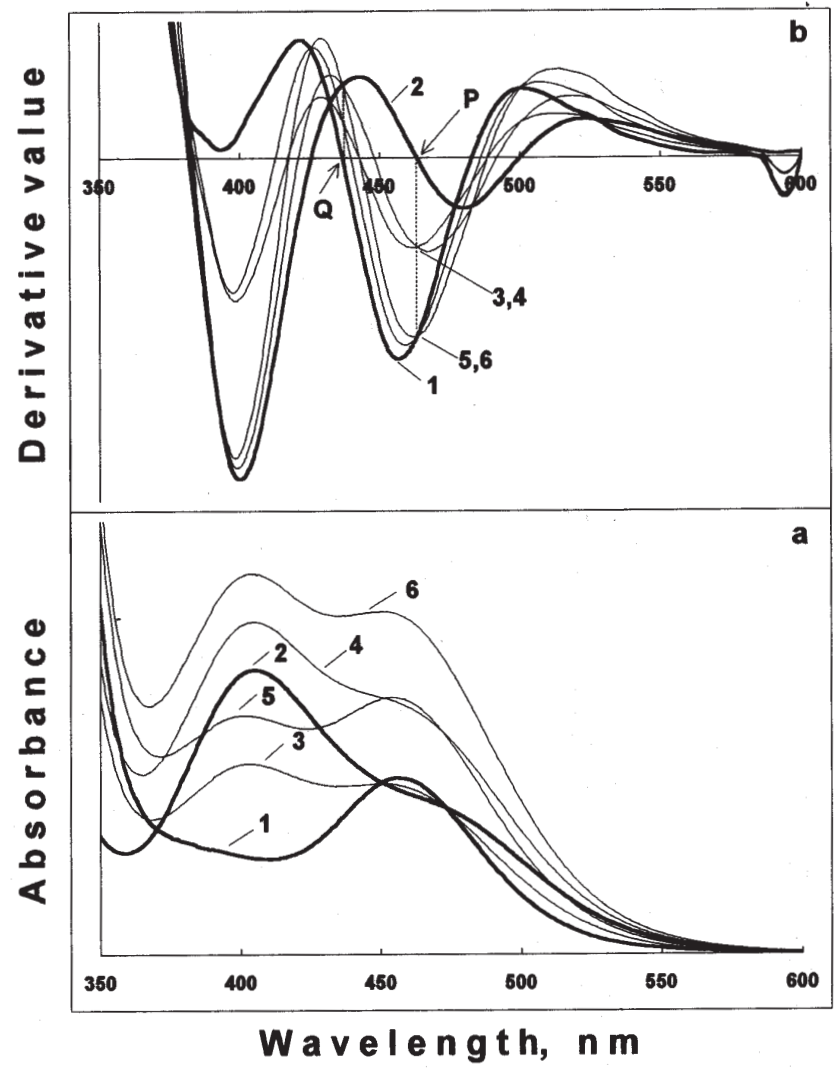

Fig. 4. Direct (a) and second-order (b) derivative spectra of the ion-pairs of ruthenium $\left(20 \mu \mathrm{g} \mathrm{ml}^{-1} \mathrm{Ru}-\right.$ curve 1$)$ and platinum $\left(20 \mu \mathrm{g} \mathrm{ml}^{-1} \mathrm{Pt}\right.$ - curve 2) with tin(II) chloride and DAM in 1,2dichloroethane; and their mixtures: $10 \mu \mathrm{g} \mathrm{ml}^{-1} \mathrm{Ru}+\left(10 \mu \mathrm{g} \mathrm{ml}^{-1} \mathrm{Pt}\right.$ and $20 \mu \mathrm{g} \mathrm{ml}^{-1} \mathrm{Pt}$ - curves 3 and 4 , respectively); $20 \mu \mathrm{g} \mathrm{ml}^{-1} \mathrm{Ru}+$ (10 $\mu \mathrm{g} \mathrm{ml}^{-1} \mathrm{Pt}$ and $20 \mu \mathrm{g} \mathrm{ml}^{-1} \mathrm{Pt}$ - curves 5 and 6 , respectively).

The "zero-crossing" point of platinum at $463 \mathrm{~nm}$ (Fig. 3c and Fig. 4b - point P) can make a basis of selective determination of ruthenium in the examined solutions. The concentration of ruthenium can be calculated from the regression equation:

$$
y=1.25 \times 10^{-6} c+3.11 \times 10^{-7} ; \mathrm{R}^{2}=0.9998 .
$$

Platinum at this wavelength does not interfere with the determination of ruthenium. Beer's law is obeyed up to $25 \mu \mathrm{g} \mathrm{ml}^{-1} \mathrm{Ru}$.

\section{Analytical application}

Four synthetic mixtures containing various amounts of platinum and ruthenium were used to evaluate the precision and accuracy of the determination of both metals by developed methods. The second derivative spectra of the ion-pairs of platinum and ruthenium with TOA and DAM isolated from their mixtures containing various amounts of analytes are shown in figure $2 \mathrm{~b}$ and figure $4 \mathrm{~b}$, respectively. It has been established that employing the system with TOA as 


\section{Original articles}

Table I. Statistical evaluation of the results of the determination of platinum and ruthenium with tin(II) chloride and TOA in synthetic mixtures by second-order spectrophotometry.

\begin{tabular}{lcccc}
\hline $\begin{array}{l}P t+R u \text { added } \\
\mu g\end{array}$ & $\begin{array}{c}P t+R u \text { found } \\
\mu g\end{array}$ & $\begin{array}{c}\text { Standard deviation } \\
P t / R u \mu g\end{array}$ & $\begin{array}{c}\text { Relative standard deviation } \\
P t / R u \%\end{array}$ & $\begin{array}{c}\text { Confidence limits } \\
P t / R u(\alpha=0.05) \mu g\end{array}$ \\
\hline $250.0+250.0$ & $247.4+240.3$ & $0.17 / 0.31$ & $1.7 / 3.2$ & $247.4 \pm 0.2 / 240.3 \pm 0.3$ \\
$250.0+625.0$ & $248.4+616.8$ & $0.18 / 0.51$ & $1.8 / 2.1$ & $248.4 \pm 0.2 / 616.8 \pm 0.5$ \\
$625.0+250.0$ & $628.6+255.0$ & $0.50 / 0.33$ & $2.0 / 3.2$ & $628.6 \pm 0.5 / 255.0 \pm 0.4$ \\
$625.0+625.0$ & $626.7+625.0$ & $0.67 / 0.70$ & $2.7 / 2.8$ & $626.7 \pm 0.7 / 625.0 \pm 0.7$ \\
\hline
\end{tabular}

${ }^{*} n=6$

extractant leads to higher precision of the results of simultaneous determination of platinum and ruthenium in organic solutions examined (Tab. I). Relative standard deviations (RSD) do not exceed $2.7 \%$ and $3.2 \%$ for platinum and ruthenium, respectively. They amounted to $4.9-11.1 \%(\mathrm{Pt})$ and $0.7-5.6 \%(\mathrm{Ru})$ in the system using DAM as extractant.

\section{Conclusions}

Extraction of platinum and ruthenium in the form of the ionpairs of the anionic complexes of both metals with tin(II) chloride and trioctylamine or diantipyrylmethane can be used for their preconcentration prior to the determination by spectrophotometric technique. The use of derivative spectrophotometry allows to determine platinum and ruthenium (up to $30 \mu \mathrm{g} \mathrm{ml}^{-1}$ each of analytes in the system with TOA) in the same solutions without their mutual separation. The method can be used for direct determination of platinum and ruthenium in binary mixtures. The other platinum metals can also form the complexes with tin(II) chloride [12] and the examined amines and can affect the results for platinum and ruthenium.

\section{References}

1. Beamish, F.E.; Van Loon, J.C. Recent Advances in the Analytical Chemistry of the Noble Metals; Pergamon Press: Oxford, 1972.

2. Van Loon, J.C.; Barefoot, R.R. Determination of the Precious Metals, Selected Instrumental Methods; Wiley \& Sons: Chichester, 1991.

3. Hartley, F.R., Ed. Chemistry of the Platinum Group Metals; Elsevier: Amsterdam, 1991.

4. Hamnett, A.; Troughton, G.L. Chem. Ind. (London) 1992, 13, 480-483.

5. Uchida, M.; Aoyama, Y; Tanabe, M.; Yanagihara, N.; Eda, N.; Ohta, A. J. Electrochem. Soc. 1995, 142, 2572-2576.

6. Aricò, A.S.; Poltarzewski, Z.; Kim, H.; Morana, A.; Giordano, G.; Antonucci, V. J. Power Sources 1995, 55, 159-166.

7. Rauche, B.R.; McLarnon, F.R.; Cairns, E.J. J. Electrochem. Soc. 1995, 142, 1073-1084.

8. Balcerzak, M.; Święcicka, E.; Balukiewicz, E. Talanta 1999, 48, 39-47.

9. Talsky, G. Derivative Spectrophotometry; VCH: Weinheim, 1994.

10. Al-Bazi, S.J.; Chow, A. Talanta 1984, 31, 815-836.

11. Young, F.J.; Gillard, R.D.; Wilkinson, G. J. Chem. Soc. 1964, 5176.
12. Balcerzak, M. Analusis 1994, 22, 353-359.

13. Dhara, S.C. Chem. Abstr. 1984, 100, 213, 533.

14. Cleare, M.J.; Charlesworth, P.; Bryson, D.J. J. Chem. Tech. Biotechnol. 1979, 29, 210-214.

15. Belova, V.V.; Khol'kin, A.I.; Muehl, P.; Gloe, K.; Khol'kina, V.N. Zh. Neorg. Khim. 1991, 36, 141-145.

16. Belova, V.V.; Kholkin, A.I.; Vasilevich, S.A.; Zhidkova, T.I.; Medkov M.A.; Shchipunov Yu, A.; Shumilina, E.V. Zh. Neorg. Khim. 1994, 39, 1856-1858.

17. Buslaeva, T.M.; Sinitsyn, N.M.; Koteneva, N.A.; Shcherbakova, E.S. Zh. Neorg. Khim. 1994, 39, 112-116.

18. Yamamoto, K.; Katoh, S. Talanta 1996, 43, 61-66.

19. Belova, V.V.; Khol'kin, A.I.; Vasilevich, S.A.; Zhidkova, T.I. Zh. Neorg. Khim., 1994, 39, 1859-1865.

20. Belova, V.V.; Zhidkova, T.I.; Khol'kin, A.I. Zh. Neorg. Khim., 1994, 39, 656-660, 1851-1855.

21. Bol'shakov, K.A.; Sinitsyn, N.M.; Buslaeva, T.M.; Ivchenko, A.P.; Dokl. Akad. Nauk SSSR, 1980, 251, 1406-1409.

22. Sinitsyn, N.M.; Buslaeva, T.M.; Malynov, I.V.; Komozin, I.V. Zh. Neorg. Khim. 1988, 33, 1526-1531.

23. Sinitsyn, N.M.; Bodnar, N.M.; Buslaeva, T.M.; Marentsova, E.V.; Malynov, I.V.; Koteneva, N.A. Zh. Neorg. Khim. 1994, 39, 117-120.

24. Busev, A.J.; Akimov, V.A. Talanta, 1964, 11, 1657-1673.

25. Bol'shakov, K.A.; Sinitsyn, N.M.; Bodnar, N.M.; Medvedev, V.I. Dokl. Akad. Nauk SSSR, 1969, 188, 628-631.

26. Meier, H.; Zimmerhackl, E.; Albrecht, W.; Bösche, D.; Hecker, W.; Menge, P.; Ruckdeschel, A.; Unger, E.; Zeitler, G. Mikrochim. Acta 1969, 826-838.

27. Bol'shakov, K.A.; Sinitsyn, N.M.; Bodnar, N.M.; Danilov, C.R. Dokl. Akad. Nauk SSSR, 1972, 206, 874-877.

28. Ionov, V.P.; Potapova, S.A.; Dubrovina, Z.N.; Zhavoronkov, N.M. Zh. Anal. Khim., 1975, 30, 955-961.

29. Sinitsyn, N.M.; Buslaeva, T.M.; Solomonova, A.S.; Andrievskii, V.N.; Vasilevskaya, T.N.; Brezhneva, L.I. Zh. Neorg. Khim. 1981, 26, 3151-3153.

30. Fu, J.; Nakamura, S.; Akiba, K. Anal. Sci., 1994, 10, 935-938; 1995, 11, 149-153.

31. Fontàs, C.; Anticó, E.; Valiente, M.; Hidalgo, M. Anal. Chim. Acta 1997, 346, 199-206.

32. Cedye, R.N.; Bozic, J.; Durbano, P.M.; Williamson, B. Talanta 1989, 36, 1055-1058.

33. Mashkina, S.V.; Gareev, R.F.; Ulakhovich, N.A.; Budnikov, G.K. Zh. Anal. Khim. 1993, 48, 1484-1492.

34. Khattak, M.A.; Magee, R.J. Talanta 1965, 12, 733-741.

35. Khattak, M.A.; Magee, R.J. Anal. Chim. Acta 1966, 35, $17-$ 23.

36. Danilova, V.N.; Shylina, G.V. Ukr. Khim. Zh. 1978, 44, 421423.

37. Savitzky, A.; Golay, M.J. E. Anal. Chem. 1964, 36, 1627-1639. 